\title{
On the Management Based on
}

\section{Characteristics of Knowledge Workers}

\author{
Jinghua $\mathrm{Wu}$ \\ School of Business Management, Shandong University of Finance, Jinan 250014, China \\ E-mail: wujh666@sina.com
}

\begin{abstract}
How to manage knowledge workers effectively is an important project for most managers. Because of knowledge workers' different characteristics from common workers, the effective management for them should be based on their unique characteristics. Therefore, a systematic, comprehensive, and pertinent management strategy is necessary.
\end{abstract}

Keywords: Knowledge employee, Empower, Redesign of work, Corporate culture

Because of the information technology revolution, the world economy has been changed from the resource- dependent industry economy toward the knowledge-dependent knowledge economy. Knowledge workers, as the main carriers of knowledge, become more and more important in the economic development of future. Due to the knowledge workers' different characteristics from common workers, the traditional management way has been challenged. How to manage knowledge workers effectively has become an important issue for many managers. Just as what was said in Peter F. Drucker's, an authority in the management field in America, Management Challenges for the 21th Century: to improve knowledge workers' productivity would become the key of management, just as one hundred years ago when to improve physical workers' productivity was the key of management (Peter F. Drucker, 2000, p16).

\section{Knowledge workers and their characteristics}

The "knowledge worker" concept was firstly advanced by Peter F. Drucker, a famous scholar in management field, in $50 \mathrm{~s}$ in 20th century. It refers to people who master and use notes and concepts, and work by knowledge and information. As they create wealth, they use brains more than hands. They bring about added values for products by their innovations, analyses, estimations, integrations, and designs. Generally speaking, managers and technologists belong to the scope of knowledge workers. Comparing with traditional physical workers, knowledge workers have following characteristics.

(1) Stronger self-determination.

Comparing with workers who have to catch up with the operation of machine passively in work flow, knowledge workers are engaged in creative work, instead of simple and repetitive procedure work. Their work does not have established procedures and processes. And the job introduction and fixed work rules are meaningless for knowledge workers. Therefore, knowledge workers have more self-determination.

(2) Greater possibility of job-hopping. On one hand, because of the speeded-up reform, an enterprise's life cycle is shortened. Knowledge workers usually have longer career life than the life of the enterprise that they work for. The enterprise can not promise for a life-long employment. On the other hand, because knowledge workers possess the main production tools, namely the implicit knowledge in their brains, they are capable of accepting new tasks and new jobs. Therefore, they have greater freedom in choosing their jobs, comparing with traditional workers. They have less dependence on the enterprise relatively. In other words, once they find the present job is short of attraction or space for personal growth and development, they may turn to other enterprises and seek for new career chance. Besides, the specialties of knowledge workers and the great social demand for knowledge provide with more chances for knowledge workers changing their jobs among enterprises, regions, and even countries.

(3) Higher demand of knowledge workers. In general, knowledge workers have accepted higher education. They possess relatively higher individual qualities and specialties in certain fields. Their salaries and life have been guaranteed in a sense. Therefore, they pursue for self-esteem and realization of self-worth. They do not satisfy with common daily work. They are wild about more challengeable and creative work. And they hope for realizing their self-worth by displaying their wisdom in the process.

(4) It is hard to control and supervise the work process. Knowledge workers undertake knowledge work under uncertain environment. The work process is usually virtual. Traditional operation rules are meaningless for them. They have greater freedom and self-determination. Even their work places are far different from traditional fixed workshops or 
offices. Their inspirations and innovations may happen in any time and space out of work time and space. Therefore, it is hard to control and supervise knowledge workers' work process.

(5) The complexity and uncertainty of work evaluation. On one hand, because knowledge workers are engaged in creative work, it is hard to set up an evaluation standard in advance. Besides, knowledge workers accomplish their work in form of certain ideas, innovations, technology innovations, and management innovation, which can not be measured directly. On the hand, because of modern science and technology's fast development, one person's specialty can not satisfy the complex job's need for knowledge. Many knowledge innovation and scientific research fruit have to be accomplished by team coordination. Take Microsoft for example. A large software is usually accomplished by nearly 500 programmers cooperated together. This trans-branch and organization cooperation has its advantages, which makes it impossible to separate the achievement. As a result, it is hard to evaluate individuals' performance.

\section{Execute effective management strategy based on characteristics of knowledge workers}

In order to achieve effective management on knowledge workers, it is necessary to constitute systematic, comprehensive, and pointed management strategy according to characteristics of knowledge workers. In specific, it includes these aspects as follow.

(1) Recognize and redefine the relationship between knowledge workers and entrepreneurs. At the industrial economy time, capitals, as the important and scarce source, determines the capital-and-employment relationship between entrepreneurs and employees. But at the knowledge economy time the traditional relationship between knowledge workers and entrepreneurs changes. Knowledge workers are not followers but partners because knowledge workers possess their own production tools, namely the knowledge stored in their brains. They are suppliers of knowledge resource. Similar to suppliers of capitals, they should have the residual claim right.

(2) Reengineer the enterprise's organization structure. Researches show that the organization structure of Chinese enterprises is too simple. 56.2 percent of enterprises adopt the unitary organization form. Even for large-scale enterprises, 54.23 percent of them adopt this kind. However, this pyramid organization structure is a kind of level management vertically, what leads to poor information communication and lower management efficiency. Horizontally, this organization form classifies branches based on specialties and responsibilities, which leads to a competitive relationship between branches. Therefore, this organization form may cause severe departmental selfishness, affecting the cooperation between branches and workers. Especially for interactive operations, different branches may tempt to escape from responsibilities. Besides, due to this leveled organization, many excellent experts and technologists focus on how to achieve further promotion instead of specialties. Practices prove that after excellent technologists became managers, the organization would confront with fatal disasters, which may lead to a great waste of talents. The principle of reforming the organization structure is to benefit the cooperation between knowledge workers and exert their potentials to a great degree. Therefore, the organization structure should be reformed toward being flatten, network, flexible, and virtual.

(3) Empowerment. The so-called empowerment means the top level empowers the low level to exert certain authority and responsibility, what makes the lower levels possess certain self-determination and freedom. An empowerment to knowledge workers has two advantages at least. Firstly, it can satisfy knowledge workers' demand for self-determination. Most knowledge workers are engaged in creative work. Too-much control may depress their creativity. Secondly, it can enhance knowledge workers' responsibilities. As empowering knowledge workers to authorities, make them shoulder relevant responsibilities. Equity of authority and responsibility is an essential principal of management. Thirdly, it can improve the quality of decision. The fast updated knowledge, together with the fact that today's managers usually do not familiarize with their followers' work, makes managers face up with such a challenge that how to manage their followers who are experts in certain fields. Empower the decision right to relevant experts. It can greatly improve the quality and efficiency of decision. The quality of decision is usually determined by the match between knowledge and decision right.

(4) Redesign of work. According to Hackman and Oldham's model, an incentive job should have five characteristics as follow: diversity of techniques, completeness of work, importance of task, self- determination, and feedback. Therefore, we can redesign the work and make it more challengeable, by which we can encourage knowledge workers. In specific, we can realize this goal by extending the scope of work, enriching the work, and the flexible work system.

To extend the scope of work is to absorb one or more relevant tasks into present job. By extending the scope of work, we can reduce the repetitiveness of short-term job, and the workers' disgusting feelings toward tedious job, adding more importance into the job. And the diversified technologies demanded by one joy will effectively encourage knowledge workers.

To enrich the work is to make knowledge workers possess a sense of achievement, acceptance, and responsibility as accomplishing a work by changing the work's contents and responsibilities' levels. As knowledge workers do not regard their present work as challengeable, managers can redeploy them to more challengeable work, which can enrich the 
work and reduce the baldness of work.

Besides, because most knowledge workers are engaged in brain work, fixed work places and time are meaningless for them. Enterprises can apply a flexible work system that permits knowledge workers adjust their work time and work place to coordinate personal need and work need. In fact, today's information technologies and official businesses provides with favorable conditions for the implement of flexible work system. By network, knowledge workers can connect with enterprises, transmitting information and data, at home anytime. Correspondingly, managers can direct and supervise knowledge workers, avoiding the malfunction of management.

(5) Emphasize the construction of corporate culture. A nice corporate culture can help employees understand and accept enterprises' value trends, adding their senses of adscription. Especially for knowledge workers who change their jobs more frequent, a sense of acceptance and adscription can sustain their loyalty to enterprises.

In constructing the corporate culture, these aspects should not be neglected.

a. Encouragement instead of punishment for failures. Because there are no rules or experiences for knowledge workers' creative work, they face higher risks. If punish failures, it will depress knowledge workers' creativity.

b. Existence of informal organization. Informal organization is formed in work by members with common values or interests. In a sense, informal organization can satisfy members' need for social acceptance, psychology, and ascription, enhancing the cohesion of organization, and driving the share of knowledge. Researches show that 70 percent of knowledge workers' knowledge obtained in work place is coming from informal communication. Most ideas come into being in chatting with colleagues, friends, and clients. However, some managers mistake informal organizations as factions, and evil parties, and strike them. As a matter of fact, it blocks the source of creativity.

c. Encourage cooperation and realize knowledge sharing. Knowledge sharing is not natural. People are not willing to share their accumulated knowledge and experiences with others, especially as knowledge sharing may lead to staff reduction or threaten their superiorities in enterprises. Therefore, in constructing the corporate culture, we should encourage the knowledge sharing among workers. In an environment with knowledge sharing, if a knowledge worker can publicize and advertise his or her specialties, he can gain respect from colleagues and important position in an organization, which are valuable return for his or her deeds. Knowledge sharing among workers can reduce or avoid the learning costs in organizations. If everyone has to learn others' knowledge, the advantages of specialization will disappear.

d. Emphasize training. At the fast-changing times, what knowledge workers pursue is not merely a job but a lifetime career. Tampoe, a knowledge management expert, think that, after lots of researches, the first four incentive factors for knowledge workers are personal growth (33.74\%), work self-determination (30.51\%), work achievement (26.69\%), and money (7.07\%). In order to satisfy workers' demand for constant growth, enterprises have to emphasize trainings, providing more training opportunities for employees.

\section{References}

Charles Despres. (2004). Knowledge horizons: the Present and Promise of knowledge management. Beijing: Posts \& Telecom Press.

Frances Horibe. (2000). Managing Knowledge Workers. Beijing: China Machine Publishing House.

Peter F. Drucker. (2000). Management Challenges for the 21th Century. Beijing: SDX Joint Publishing Company.

Jianming, Li. (2004). Difficulties and suggestions for China's corporate management in 21th century. China Enterprise News. 16th, March. 